\title{
NUTRITIVE AND MEDICINAL PROPERTIES OF DANDELION (TARAXICUM OFFICINALE): A REVIEW
}

\author{
${ }^{1}$ D.A. Tuwar* and ${ }^{2}$ A.A. Kulkarni \\ Department of Botany, Ahmednagar College, Ahmednagar, Dist. Ahmednagar, MS (India) \\ *Corresponding Author: tuwarda91@gmail.com
}

Communicated : 15.02.2020

ABSTRACT:

Revision : 19.3.20 \& 10.04.2020

Accepted : 18.05 .2020

Published: 30.05.2020

\begin{abstract}
Taraxacum officinale (Dandelion) is a herbaceous perennial herb belonging to family Asteraceae. Dandelion (Taraxacum $s p p$ ) is used in many traditional and modern herbal medical systems. The root is chiefly considered a gastrointestinal medicine, supporting digestion and liver function, while the leaf is used as a diuretic and bitter digestive stimulant. The leaf of Taraxacum officinale that is Dandelion has been studied for its chemical properties and also for their nutritional value. From literature revealed that Taraxacum officinale (dandelion) is widely used in traditional and natural medicine systems. Different parts of this herbal plant has anti-diabetic effect, hepatoprotective effects, Antiinflammatory actions, Anti-oxidative properties, Antifibrotic Effects, Inhibitory effect on HIV-1 replication and reverse transcriptase activity and anticancer effects. Since, there are insufficient data from well conducted clinical trials so, extensive in-vitro, in-vivo, and clinical research is necessary to inspect further the pharmacological, physiological, and biochemical mechanisms underlying the health promoting effects of dandelion to promote its usage for therapeutic purposes.
\end{abstract}

Key words: - Taraxacum, Nutritive, Medicinal, dandelion.

\section{INTRODUCTION:}

It was reported in history that herbs are used to treat diseases, health gain and a food source as its nutritional value has been common in human societies. Many drugs are being isolated and extracted from herbs. The medicinal plants and herbs are the sources of secondary metabolites, essential oils of therapeutic importance and nutrients. (Fatima, Tabasum, Omar Bashir, Bazila Naseer and Syed Zameer Hussain, 2018). Dandelion (Taraxacum spp.) is used in many traditional and modern herbal medical systems, as has been documented particularly in Asia, Europe, and North America. The root is chiefly considered a gastrointestinal medicine, supporting digestion and liver function, while the leaf is used as a diuretic and bitter digestive stimulant. (Eric Yarnell, Kathy Abascal, 2009). The leaf of Taraxacum officinale that is Dandelion has been studied for its chemical properties and also for their nutritional value. (N.L. Escudero, S. Fernandez, et.al., 2003). Taraxacum officinale (Dandelion) is a herbaceous perennial herb belonging to family Asteraceae (Damylo S, 1984). This herb typically has deeply toothed hairless leaves, $5-30 \mathrm{~cm}$ in length and $1-10 \mathrm{~cm}$ in width. It grows up to $3-35 \mathrm{~cm}$ in height and form a rosette structure of leaves. It has single, golden yellow flowers on straight leafless hollow stems, which develop from the center of the rosette structure. Dandelion plants have tap roots, narrowing from 2 to $3 \mathrm{~cm}$ wide and at least $15 \mathrm{~cm}$ long. Roots are fleshy and stiff, dark brown color on the outside and white on the inside (Fatima, Tabasum, Omar Bashir, Bazila Naseer and Syed Zameer Hussain, 2018).

Dandelions are among the more distinguishable weeds in the world. The English name dandelion is an exploitation of the French dent de leon, meaning "lion's tooth." The herb is similarly named in many Indo-European tongues, also being called "lion's tooth" in 
German (Löwenzahn) and Spanish (diente de leon). The name denotes to the toothed margins of the leaves. It has also been called fairy clock in English, however the reason for this name is unknown. Dandelion is also known pu2 gong1 ying 1 in Chinese (the numbers depict tone), hokouei in Japanese, and p'ogongyong in Korean. The Latin name Taraxacum is from the Greek and means "disease remedy." (Eric Yarnell, Kathy Abascal, 2009).

It is a rich source of vitamins and minerals and especially rich in vitamins $\mathrm{A}$ and $\mathrm{C}$ and iron, it carries more iron and calcium than spinach (Ali Z., 1989). The amount of vitamin $\mathrm{C}$ in fresh leaves of Dandelion is $121.862 \mathrm{mg} / \mathrm{kg}$ determined by HPLC(Paduret S., Amariei S., Gutt G., and Piscuc B., 2015). The chemical constituents for $100 \mathrm{gm}$. of dry material was: Protein 15.48 gm. ; ash 14.55 gm. ; and total dietary fiber: $47.80 \mathrm{gm}$. ; $\mathrm{Ca}: 695 \mathrm{mg}$ and $\mathrm{P}$ value was $700 \mathrm{mg}$. it also contains unsaturated fatty acids in that $50.74 \%$ corresponds to Linolenic acid (N.L. Escudero, S. Fernandez, et.al., 2003). Dandelion leaves are good source of supplementary protein as compare to vegetables and fruits (Abdel E. Ghaly, Nesrreen Mahmoud and Deepika Dave, 2012). Dandelion used as an additive in the production of Coffee and its extracts is used as a flavoring agent in many food products(Paduret S., Amariei S., Gutt G., and Piscuc B., 2015). T. officinale is rich in various antioxidants and it having a direct effect on health of organism (Williams C., Goldstone F., and Greenham J., 1996). The extracts or juices from its roots are known to liver stimulant. It having antispasmodic effect on the bile ducts and gall bladder (Hassan H., 2015). The decoction of whole plant used to treat diabetes and also as laxative and diuretic.(Hernandez-Galicia, 2002).

Chemical Composition:
Between the important compounds in dandelion are sesquiterpene lactones mainly taraxacin and taraxacerin (Leung A. Y., 1996). In addition it include beta-amyrin, taraxerol, and taraxasterolas well as free sterols (sitosterin, phytosterin and stigmasterin,), phenylpropanoids, triterpenoids aponins and polysaccharides (primarily fructosans and inulin), smaller amounts of pectin, resin. Three flavonoid glycosides - luteolin7-glucoside and two luteolin 7-diglucosides - isolated from its leaves and flowers. Hydroxycinnamic acids, chicoric acid, monocaffeyltartaric acid, and chlorogenic acid are present in throughout the plant, and the coumarins, cichoriin, and aesculin have been recognized in the leaf extracts (Williams C., Goldstone F., and Greenham J., 1996). Dandelion leaves are a rich source of a variety of vitamins including beta carotene, non-provitamin A carotenoids, xanthophylls, chlorophyll, vitamins $\mathrm{C}$ and $\mathrm{D}$, many of the B-complex vitamins,(Harrington $\mathrm{K}$. C., Thatcher A. \& Kemp P.D., 2006)and minerals like iron, silicon, magnesium, sodium, potassium, zinc, manganese, copper, and phosphorous(Agnese Giacomino et. al., 2016).

\section{Action mechanisms of dandelion in Type -2 diabetes (T2D)}

There are a evidences for the effects and mechanisms of Taraxacum on T2D might be its interaction with factors concern in the metabolic syndrome (lipid metabolism, glucose metabolism, protein metabolism, $\mathrm{a}$ - and $\beta$-cells dysfunction) (Grundy SM, Brewer HB, Cleeman JI, Smith SC, Lenfant C., 2004). The mechanisms by which plant-derived compounds manifest their anti-diabetic properties are (Mir MA, Sawhney SS, Jassal MM., 2015)

1. Inhibition of renal glucose reabsorption.

2. Decrease in the action of a-amylase with $\beta$ galactosidase and a-glucosidase. 
3. Decrease of dietary blood sugar.

4. Inhibition of potassium channel flow.

\section{Anti-inflammatory action}

Dandelion leaf extract has anti-inflammatory properties, which may protect against cholecystokinin-induced acute pancreatitis in rats. (Seo S, Koo H, An H, Kwon K, Lim B, 2005). Taraxacum officinale has been used to cure liver and gallbladder disorders, which is because of terpenoid and bitter sterol components such as taraxacin and taraxacerin. Taraxacum officinale induces apoptosis of human hepatoma (HepG2) cells through tumor necrosis factor a (TNF-a) and interleukin (IL) 1a secretion, implying anti-inflammatory effects within the central nervous system. (Koo HN, Hong SH, Song BK, Kim CH, Yoo YH, Kim HM., 2004).

\section{Anti-oxidative properties:}

Dandelion, a natural antioxidant compound has been empirically used due to its healthpromoting properties as an anti-carcinogenic, anti-inflammatory and anti-oxidant(You Y, Yoo S, Yoon HG, Park J, Lee YH, Kim S et al., 2010). Dandelion extract provides anti-oxidant defence for Excess ROS production is known from several studies conducted both in vitro and in vivo. (You Y, Yoo S, Yoon HG, Park J, Lee YH, Kim S et al., 2010). Dandelion's Flowers has potential antioxidant source, exerting their effect due to their rich content of phenolic components including flavonoids, coumaric acid, and ascorbic acid. Effective hydrogen donors are found in leaf extracts, hydrogen peroxide scavengers, and reducing agents. Various studies have demonstrated the anti-oxidative effect of Taraxacum. Dandelion leaf and root are hydrogen-donating, ROS formation-inhibiting, and radical-scavenging (Hagymasi $\mathrm{K}$, Blazovics A, Feher J, Lugasi A, Kristo ST,Kery A., 2000).

Action of dandelion on digestion, glycolysis, and Krebs cycle
Bioactive components in dandelion may be able to regulate glycolysis and Krebs cycle pathways, possibly via inhibition of certain enzymes that digest carbohydrates(Prabhakar PK, Doble M., 2008). The pathways involved are the glycolytic cycle and Krebs cycle, in addition to other pathways involved in the release of insulin from $\beta$-cells. Chlorogenic acid and chicory acid(CRA) may activate glucokinase in glycolysis, which catalyzes the phosphorylation of glucose to glucose-6-phosphate(G6P) (Coman C, Rugina OD, Socaciu C., 2012). Bioactivecomponents from medicinal plants such as dandelion are known to regulate enzymes such as hexokinase, glucokinase, and phosphofructokinase. These enzymes are involved in the processes of glycolysis and the Krebs cycle.

\section{Hepatoprotective Effects}

Ethanolic Taraxacum officinale leaves and root extract significantly attenuated marker enzymes of liver toxicity, aspartate and alanine transaminases, lipid peroxidation and oxidative stress induced by acetaminophen in mice. The Taraxacum officinale extract have shown to possess the free radical quenching activities. This protective effects of Taraxacum officinale have been suggested due to the presence of phenolic compounds in the extract (Colle D, Arantes LP, Gubert P, da Luz SC, Athayde ML,Teixeira Rocha JB et al., 2012). The efficacy of Taraxacum officinale ethanolic leaves extract was found to be more effective as compared with n-hexane extract and silymarin against $\mathrm{CCl} 4$ induced hepatotoxicity and oxidative stress in rats(Ahmed D, Gulfraz M, Ahmad MS, Tahir RM, Anwar P., 2013).

In $\mathrm{CCl} 4$ induced oxidative stress model Taraxacum officinale extract reversed the glutathione (GSH) depletion, up-regulation of Nuclear factor-kB (NF-kB) and increased expression of regulatory inflammatory mediators, such as inducible nitric oxide 
I J R B A T, Issue (VIII), Vol. II, May 2020: 17-22

A Double Blind Peer Reviewed Journal
e-ISSN $2347-517 X$

Review Article synthase (iNOS), cyclooxygenase (COX)-2, Tumor necrosis factor- a (TNF-a) and interleukin (IL)-1a (Koh YJ, Cha DS, Ko JS, Park HJ, Choi HD, 2010). These results suggest that Taraxacum officinale have a hepatoprotective effect by modulating inflammatory responses and ameliorating oxidative stress. The protective effects of Taraxacum officinale root against alcoholic liver damage were investigated In vitro in HepG2/2E1 cells (You Y, Yoo S, Yoon HG, Park J, Lee YH, Kim S et al., 2010).

\section{Antifibrotic Effects}

Hepatic fibrosis is common sequel following chronic liver injury and reversal of fibrosis prior it attains the cirrhotic stage would be a clear therapeutic strategy (Lee YA, Wallace MC, Friedman SL., 2015). Taraxacum officinale extract has been studied against the drug and chemical induced hepatic fibrosis in experimental animals and came out with promising results. The study suggested that administration of Taraxacum officinale promote the complete regression of fibrosis and the enchantment of hepatic regenerative capabilities.

\section{Anticancer Activity}

Recent study showed that natural product those present in Taraxacum root extract, have great potential as non-toxic and effective alternatives to conventional modes of chemotherapy available today. Dandelion has been said to induce cytotoxicity in Hep G2 cells and decreases its viability below 40\% (You Y, Yoo S, Yoon HG, Park J, Lee YH, Kim S et al., 2010) Taraxacum officinale extract significantly induced the secretion of TNF-a and IL-1 a and apoptosis of Hep G2 cells (Koo HN, Hong SH, Song BK, Kim CH, Yoo YH, Kim HM., 2004). These studies are clearly implicated in anticancer activity of dandelion.

Inhibitory effect on $\mathrm{HIV}-1$ replication and reverse transcriptase activity
Pseudo typed viruses produced in this system can mimic most stages of the HIV-1 life cycle, including viral protein production, assembly, release, maturation, entry, integration and replication without producing replicationcompetent viruses. This approach has the potential to identify inhibitors against multiple viral and cellular functions essential for HIV replication (Kremb S, Helfer M, Heller W, Hoffmann D, Wolff $\mathrm{H}$, Kleinschmidt A et al. , 2010). The level of HIV-1 replication has been assessed by the expression of reporter genes represented by the percentage of GFP-positive cells. Reverse transcriptase assay kit was used to detect inhibitory effect on RT enzyme activity of dandelion. These results suggest that dandelion extract has a powerful inhibition activity against HIV-1 replication and RT activity.

\section{CONCLUSION:}

The findings from literature revealed that Taraxacum officinale (dandelion) is widely used in traditional and natural medicine systems worldwide. Taraxacum officinale (dandelion) has a considerable antioxidant capacity as the leaves are rich in vitamin $\mathrm{C}$, flavonoids and carotenoids. It can be a readily available source of minerals and antioxidants in human diet. Physico-chemical and sensory qualities of dandelion recommend to use its leaves as fresh salad, flowers and roots in acidic dairy or cheese for the content in carotenoids, chlorophyll and fiber that raise the nutritional value and appearance of products. Some promising research has been done with underlying reasons to screen different parts of this herbal plant for their anti-diabetic effect, hepatoprotective effects, Anti-inflammatory actions, Antioxidative properties, Antifibrotic Effects, Inhibitory effect on HIV-1 replication and reverse transcriptase activity and anticancer effects. 
Since, there are currently insufficient data from well conducted clinical trials so, extensive invitro, in-vivo, and clinical research is necessary to inspect further the pharmacological, physiological, and biochemical mechanisms underlying the health promoting effects of dandelion to promote its usage for therapeutic purposes.

\section{REFERENCES:}

Abdel E. Ghaly, Nesrreen Mahmoud and Deepika Dave. (2012). Nutrient Composition of Dandelions and its potential as Human Food. American journal of Biochemistry and Biotechnology, 8 (2), 118-127.

Agnese Giacomino et. al. (2016). Metal Content in Dandelion (Taraxacum officinale) leavesinfluence of Venicullar Traffic and safety upon consumption as Food. Journal of Chemistry, 1-9.

Ahmed D, Gulfraz M, Ahmad MS, Tahir RM, Anwar P. (2013). Cytoprotective potential of methanolic leaves extract of Taraxacumofficinale on $\mathrm{CCl} 4$ induced Rats. Pensee Journal, 75:220-227.

Ali Z. (1989). Medicinal plants. Iran: Tehran University Press.

Colle D, Arantes LP, Gubert P, da Luz SC, Athayde ML,Teixeira Rocha JB et al. (2012). Antioxidant properties of Taraxacumofficinaleleaf extract are involved in the protective effect against hepatoxicity induced by acetaminophen in mice. . Journal of Medicine and Food, 15(6):549-556

Coman C, Rugina OD, Socaciu C. (2012). Plants and natural compounds with antidiabetic action. Notulae Botanacae Horti Agrobotanici Clujnapoca, 40(1):314-325.

Damylo S, F. S. (1984). Plant species of Plant Cosmetics- Health. Iran: Gilan University Press, Rasht.

Eric Yarnell, Kathy Abascal. (2009). Dandelion (Taraxacum officinale and $T$. mongolicum). Integrative medicine, 8: 35-38.

Fatima, T. O. (2018). Dandelion: Phytochemistry and Clinical potential. Journal of Medicinal Plant Studies, 6(2):198-202.

Grundy SM, Brewer HB, Cleeman JI, Smith SC, Lenfant C. (2004). Definition of metabolic syndrome: Report of theNational Heart, Lung, and Blood. America: Institute/American Heart Association conference on scientific issues related to definition. Circulation.

Hagymasi K, Blazovics A, Feher J, Lugasi A, Kristo ST,Kery A. (2000). The in vitro effect of dandelions antioxidantson microsomal lipid peroxidation. Phytother Research, 14(1):43-44.

Harrington K. C., Thatcher A. \& Kemp P.D. (2006). MINERAL COMPOSITION AND NUTRITIVE VALUE OF SOME COMMON PASTURE WEEDS. New Zealand Plant Protection, 59: 261-265.

Hassan H., K. E. (2015). Comparative and Protective effect of Moringa and Dandelion extracts against hepatic disorders and Oxidative stress associated with prolonged use of brufen drug in rats. The Egyptian Journal of Hospital Medicine, 60: 336- 346. 
Hernandez-Galicia, E. A.-C.-S.-R.-M.-V.-S.-A. (2002). Studies on hyperglycemic activity of Mexican medicinal plants. Proc. West Pharmacological Society , 45: $118-124$

Koh YJ, Cha DS, Ko JS, Park HJ, Choi HD. (2010). Anti Antiinflammatory effect of Taraxacumofficinale leaves on lipopolysaccharide-induced inflammatory responses in RAW 264.7 cells. . Journal of Medicine and Food, 13:870-878.

Koo HN, Hong SH, Song BK, Kim CH, Yoo YH, Kim HM. (2004). Taraxacumofficinale induces cytotoxicitythrough TNF-alpha and IL-1alpha secretion in Hep G2 cells. Life Sciences, 74(9):1149-1157.

Kremb S, Helfer M, Heller W, Hoffmann D, Wolff H, Kleinschmidt A et al. . (2010). EASYHIT: HIV full-replication technology for broad discovery of multiple classes of HIV inhibitors. Antimicrob Agents Chemother., 54:5257-5268.

Lee YA, Wallace MC, Friedman SL. (2015). Pathobiology of liver fibrosis: a translational success story. Gut., 2015; 64:830-841.

Leung A. Y., F. S. (1996). Encyclopedia of common natural ingredients used in food, drugs and cosmetics. New York: John Wiley and Sons.

Mir MA, Sawhney SS, Jassal MM. (2015). Invitro antidiabetic studies of various extracts of Taraxacumofficinale. PharmaInnov, 4(1):61-66.

N.L. Escudero, S. Fernandez, et.al. (2003) Taraxacum officinale as a food source. Plant Foods for human nutrition , 58, 110.

Paduret S., Amariei S., Gutt G., and Piscuc B. (2015). The Evaluation of Dandelion ( ) properties as a Valuable Food Ingredient. Romanian Biotechnological Letters, 21: 11569-11575.

Prabhakar PK, Doble M. (2008). A target based therapeutic approach towards diabetes mellitus using medicinal plants. Current Diabetes Review, 4(4):291-308.

Seo S, K. H. (2005). Taraxacumofficinaleprotects against cholecystokinin-induced acute pancreatitisin rats. World $J$ Gastroenterol, 11(4):597-599.

Williams C., G. F. (1996). Flavonoids, Cinnamic acids and Coumarins from the different tissues and medicinal preparations of Taraxacum officinale. Phytochemistry, 42: 121-127.

You Y, Yoo S, Yoon HG, Park J, Lee YH, Kim S et al. (2010). In vitro and in vivo hepatoprotective effects of the aqueous extract from Taraxacumofficinale (dandelion) root against alcoholinducedoxidative stress. Food Chemistry Toxicology, 48(6):1632-1637. 